\title{
Testing Innovative Technique Based on Microwave Irradiation, for Stimulating Common Bean Germination and Development
}

\author{
Claudia BALINT ${ }^{1}$, Ioan OROIAN ${ }^{1 *}$, Emanoil SURDUCAN ${ }^{2}$, Bianca BORDEANU ${ }^{1}$, \\ Daniela BORDEA ${ }^{1}$ \\ ${ }^{1}$ Faculty of Agriculture, University of Agricultural Sciences and Veterinary Medicine Cluj - Napoca, \\ Mănăştur St., No. 3 - 5, 400327 Cluj-Napoca, Romania \\ ${ }^{2}$ National Institute of Research and Development for Isotopic and Molecular Technologies, Donat St., \\ No. 67 -103, 4002993 Cluj - Napoca, România. \\ * corresponding author: neluoroian@gmail.com \\ Bulletin USAMV series Agriculture 72(1)/2015 \\ Print ISSN 1843-5246; Electronic ISSN 1843-5386 \\ DOI 10.15835/buasvmcn-agr: 11194
}

\begin{abstract}
In the last decades a new goal for agriculture is to develop environmentally friendly innovative technologies. One of the interest solutions, in perspective, is the treatment of plants with low power microwave irradiation in order to obtain a higher and healthier production. This approach could also contribute to mitigation of harmful effects produced by excessive use of chemical products in treatment of seeds and also field culture phytoprotection. Investigating effects of microwave irradiation, on the germination of common bean (Phaseolus vulgaris L. cv. Ardeleana) seeds, and on the growth and development of bean plantules, in specific experimental conditions. The trial was developed within Laboratories of the Advanced Research Centre for Environmental Protection and Assessment of Life Quality from USAMV Cluj-Napoca. The growing experiment of 10 - 8 days (with 49 individuals each) was developed until the seeds have grown up to $15 \mathrm{~cm}$ height, in conditions of microwave irradiated and no irradiated conditions. The studied parameters were: length of stems, length of roots, and seedling vigour index. Data were statistically processed with STATISTICA v 6.0 Office. The studied parameters were quantified by biometric approach (length of stems and roots). The use of low power microwave irradiation in germination of common bean in laboratory conditions may be taken into consideration for large scale cultivation. Further research is needed in order to establish appropriate practices for the success of this innovative technique.
\end{abstract}

Keywords: treatment, magnetic field, basic statistics.

\section{INTRODUCTION}

Lot of research is performed in the field of vegtable with valuable importance in different life fields (Odagiu et al., 2012). One of theese is the common bean.

The common bean is an important species with a long history of cultivation for dry fruits and pods used on people alimentation in a large culinary assortment. The leaf is also occasionally used as a vegetable, and the straw can be used for fodder.
The use of physical factors in behaviour of increasing production of different cultures combining with the newest ecological technologies it is important for the agriculture of our century. Most perspective methods for increasing the crops production are based on the impact of magnetic field, laser and electromagnetic irradiation, ultrasounds influence, etc. (Munteanu et al., 2011; Surducan et al, 2012). 
They are supposed to supply bigger amounts of the necessary energy, and accelerate the plant growth and development. All living processes are highly dependent on energy exchange between the cell and the environment (Aladjadjiyan, 2007).

Racuciu et al. (2008) demonstrate that the magnetic exposure to low static magnetic field $(50 \mathrm{mT})$ revealed the stimulatory influence on the plants in their early ontogenetic stages and the cultivation of plants under low magnetic field could be the background of crop improving in the frame of future agricultural techniques. Results obtained by Aladjadjiyan (2011) show the effect of ultrasonic treatment on the development of seeds from lentils (Lens culinaris, Med.) and wheat (Triticum aestivum). The above mentioned research concluded that ultrasonic treatment with frequency $42 \mathrm{kHz}$ of lentil and wheat seeds improves the early stages of plants growth. Podlesny et al. determined the changes of some biochemical and physiological processes, which occurred in seeds and seedlings of white lupine and faba bean after pre-sowing treatment with laser beams (Podelsny et al., 2012). The irradiated seeds of white lupine and faba bean had higher fresh weight at the time of imbibition than the seeds which were not treated with laser beams. It resulted in earlier and more uniform germination.

One of the interest solutions, in perspective, is the treatment of plants with low power microwave irradiation in order to obtain a higher and healthier production. In this direction Lakshmappa et al. (2011) tested the effects of low-power microwave fields on seed germination and growth rate (Lakshmappa et al., 2011). Experiments were performed in X-band frequencies using klystron based microwave test bench. The seed samples used for the experiment included wheat (Triticum aestivum), bengal gram (Cicer arietinum), green gram (Vigna radiate) and moth bean (Vigna Aconitifolia). Cretescu et al.(2013) investigated the changes induced upon germination and growth rate, expressed by vigor index of barley seeds exposed to microwave (MW) treatment). As a microwave source was used a magnetron MWG20H, which emits radiation with a frequency of $2.45 \mathrm{GHz}$.

\section{MATERIALS AND METHODS}

The aim of this research was to investigate the effects of microwave irradiation, on the germination of common bean (Phaseolus vulgaris L. cv. Ardeleana) seeds, and on the growth and development of bean plantules, in specific experimental conditions.

The trial was developed within Laboratories of the Advanced Research Centre for Environmental Protection and Assessment of Life Quality from USAMV Cluj-Napoca.

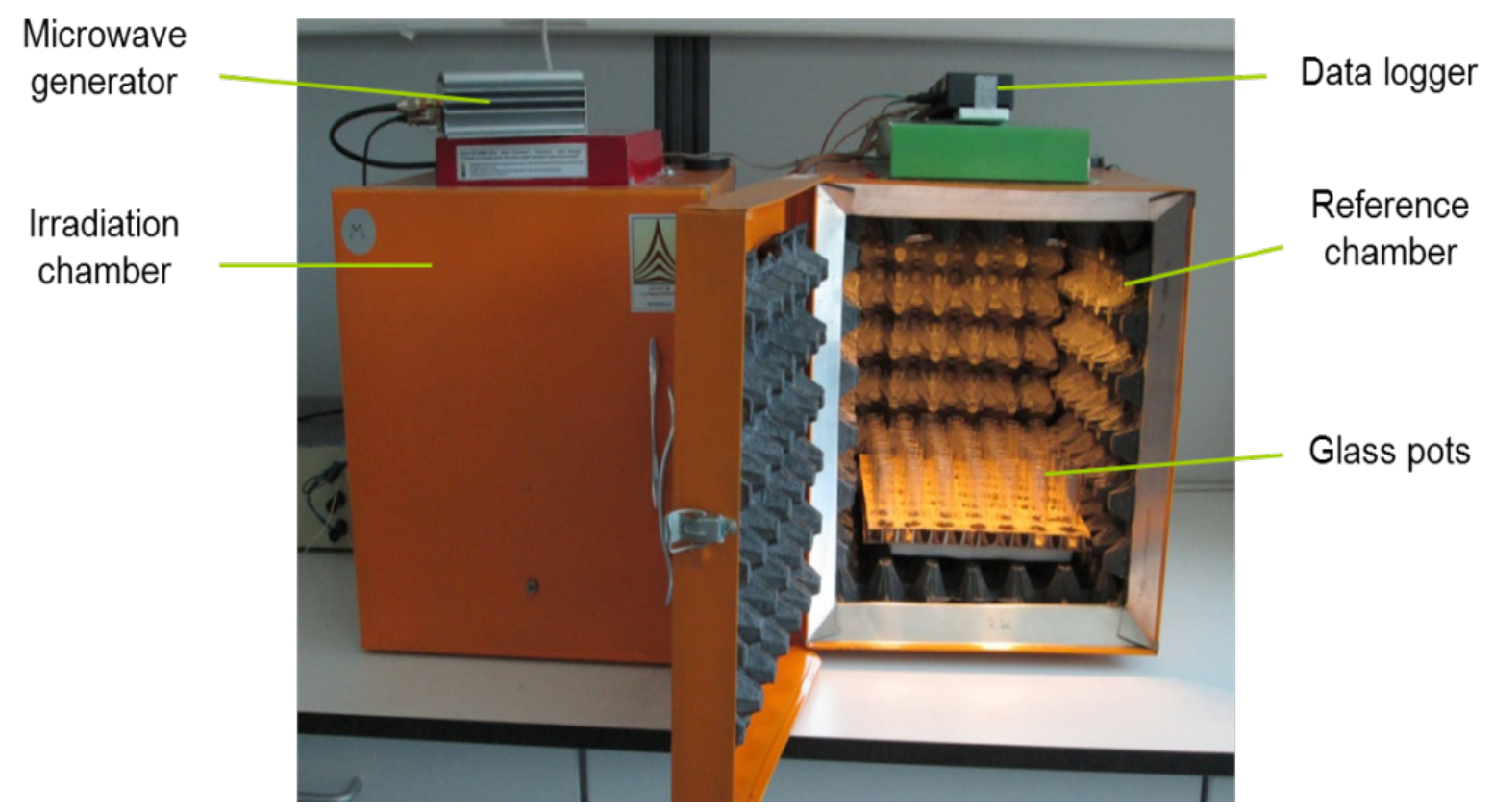

Figure 1. The experimental setup [9]. 
The device set for plant growth in low microwave field under controlled environment are designed, manufactured and tested at the National Institute for R\&D of Isotopic and Molecular Technologies Cluj-Napoca.

For microwaves exposure, two identical anechoic chambers were used: reference chamber (R) and an irradiation chamber (I), both with controlled environment (identical humidity, temperature, light intensity and radiofrequency isolation to/from the external environment).

Specific environmental conditions for germination and plant growth process of bean were tested for each factor.

Plants are sensitive to light intensity, its spectral composition and alternating of light and dark periods. Light is necessary condition for photosynthesis - most important process in plants' life.

On our case the LED lamps intensity has been calibrated at $100 \mu \mathrm{mol} \mathrm{s}^{-1} \mathrm{~m}^{-2}$. The light intensity was verified every week during the experiment in four points at the chambers floor.

Phaseolus vulgaris L. it is a thermophile plant with needs on vegetation period of 15$20^{\circ} \mathrm{C}$. Seed germination is particularly affected by temperature. The seeds germinated at $8-10^{\circ} \mathrm{C}$ (the optimal temperature being $32^{\circ} \mathrm{C}$ ).

The favorable temperature for growth it is abouth $20^{\circ} \mathrm{C}$ [9]. Bigger values accompanied by water scarcity, high temperature oscillations along the vegetation period also can lead to decreased germination percentage and decrease the number of plants. Compared to water, beans have moderate requirements but different depending on vegetation phases.

For temperature and humidity a data logger has been programmed on experiment to sample the inside of chambers and to equalize the humidity within $\pm 3 \%$.

During photosynthesis, plants use energy in the region of the electromagnetic spectrum from 400-700 $\mathrm{nm}$. The radiation in this range, referred to as Photosynthetically Active Radiation (PAR), can be measured in energy units (watts $\mathrm{m}^{-2}$ ) or as Photosynthetic Photon Flux Density (PPFD) which has units of quanta (photons) per unit time per unit surface area. The scaled units most commonly used are micromoles of quanta per second per square meter $\left(\mu \mathrm{mol} \mathrm{s}^{-1} \mathrm{~m}^{-2}\right)$ [10].
The microwave generator used for Phaseolus vulgaris L. irradiation has been set to GSM900, frequency range $890-915 \mathrm{MHz}$ and the power level at the irradiation chamber floor has been set to $-20 \mathrm{dBm}$, corresponding to a microwave power density of $1.28 \mathrm{~mW} / \mathrm{m}^{2}$.

After the settings of the experimental condition have been made, we elaborated an experimental protocol for seed germination and plant development.

First the bean seeds have been preliminarily washed with distilled water in order to eliminate the possible impurities. Groups of 49 seeds were placed on a support plate in the two anechoic chambers with controlled environment, (identical temperature and relative humidity) inside the reference (R) and irradiation chamber (I), similar lighting conditions and water dosage.

The seeds were germinated in small glass pots $(\varnothing=2 \mathrm{~cm}$ and $\mathrm{h}=6 \mathrm{~cm})$, one seed in each pot, on wet cotton, covered with filter paper. To avoid seeds drying and to maintain humidity of the filter paper for plants growth process, $2 \mathrm{~mL}$ of potable water was added in the first day of the experiment and $0.2 \mathrm{ml}$ periodically. No other substances were added in the water and to seeds.

To estimate the influence of the microwave treatment on bean seeds, the studied parameters were:

the length of stems (SL, cm), determined on the half at the experiment and at the end;

the length of roots (RL, cm), determined on the half at the experiment and at the end;

the seedling vigor index (SVI), was calculated by determining germination percentage and seedling length of the same seed lot.

For the entire process from seeds to plants, we made the tests for different experimental periods. According with SR 1634/99 the seeds germination for bean it has been verified on $5^{\text {th }}$ day for GE and $9^{\text {th }}$ day for $\mathrm{G}$.

On our conditions we started the experiment with 10 days, but the plants growth to much. So we decided to short the experiment with 2 days.

Data were statistically processed with STATISTICA v 6.0 Office. Basic statistics was used for emphasizing the evolution of bean seeds within and without irradiated environment, and Student test was used in order to calculate the significance of differences between 


\section{RESULTS AND DISCUSSIONS}

Three growing experiments of 8 days each (with 49 individuals each) was developed till the seeds have grown to about $15 \mathrm{~cm}$ height, in microwave irradiated and non-irradiated conditions.

At mid-term of experiment development the average stem length was of $1.33 \mathrm{~cm}$ and average root length of $1.25 \mathrm{~cm}$ in non-irradiated conditions (Table 1), while in irradiated field stem length was of $1.63 \mathrm{~cm}$ and average root length of $1.40 \mathrm{~cm}$ (Table 2).

In the end of the experimental period, the average stem length was of $6.89 \mathrm{~cm}$, average root length of $5.81 \mathrm{~cm}$, and vigor index of $1057.96 \%$ in non-irradiated conditions (Table 3), while in irradiated field stem length was of $1.63 \mathrm{~cm}$, average root length of $1.40 \mathrm{~cm}$, and vigor index of $1142.45 \%$ (Table 4).

According to dispersion parameters and coefficients of variance, Basic statistics indicates that in both irradiated and non-irradiated experimental conditions the developmental process is an impredictible, and discontinuous one.

The results of testing the significance of differences between the stem length, roots length, and vigor index within non-irradiated and irradiated electromagnetic field at both mi-term and end of developmental process (Tables 5 and 6) show that electromagnetic field stimulates the bean seeds development, but in an insignificant manner ( $p>0.05)$, the differences being not significant at above mentioned significance threshold.

At mid-term of developmental process, the average stem length of bean plants placed in electromagnetic field was with $0.30 \mathrm{~cm}$ bigger compared to those non-irradiated, while average root length was bigger with $0.14 \mathrm{~cm}$ in bean plants placed in electromagnetic field was with $0.30 \mathrm{~cm}$ bigger compared to those non-irradiated (Table 5).

In the end of the experimental period, the average stem length of bean plants placed in electromagnetic field was with $0.82 \mathrm{~cm}$ bigger compared to those non-irradiated, average root length was bigger with $0.86 \mathrm{~cm}$ in bean plants placed in electromagnetic compared to those non-irradiated, while vigor index was bigger with $84.49 \%$ in bean plants placed in electromagnetic compared to those non-irradiated (Table 6), as show our results.

Tab. 1. Basic statistics for the development of non-irradiated bean seeds, 8.06.2014

\begin{tabular}{ccccccc}
\hline Issue & $\mathrm{n}$ & $\mathrm{X} \pm \mathrm{S}_{\mathrm{\gamma}}$ & $\mathrm{s}$ & $\mathrm{CV} \%$ & Skewness & Kurtosis \\
\hline Stem length, $\mathrm{cm}$ & 49 & $1.33 \pm 0.25$ & 1.74 & 130.52 & 1.49 & 1.56 \\
Root length, $\mathrm{cm}$ & 49 & $1.25 \pm 0.19$ & 1.35 & 107.34 & 0.56 & 1.30 \\
\hline
\end{tabular}

Tab. 2. Basic statistics for the development of irradiated bean seeds, 8.06.2014

\begin{tabular}{ccccccc}
\hline Issue & $\mathrm{n}$ & $\mathrm{X} \pm \mathrm{S}_{\mathrm{y}}$ & $\mathrm{s}$ & $\mathrm{CV} \%$ & Skewness & Kurtosis \\
\hline Stem length, $\mathrm{cm}$ & 49 & $1.63 \pm 0.25$ & 1.76 & 107.87 & 1.26 & 0.83 \\
Root length, $\mathrm{cm}$ & 48 & $1.40 \pm 0.20$ & 1.38 & 98.48 & 0.90 & 0.22 \\
\hline
\end{tabular}

Tab. 3. Basic statistics for the development of irradiated and non-irradiated bean seeds, 11.06.2014

\begin{tabular}{ccccccc}
\hline Issue & $\mathrm{n}$ & $\mathrm{X} \pm \mathrm{S}_{\mathrm{y}}$ & $\mathrm{S}$ & $\mathrm{CV} \%$ & Skewness & Kurtosis \\
\hline Stem length, $\mathrm{cm}$ & 49 & $6.07 \pm 0.59$ & 4.12 & 67.87 & 0.32 & 0.54 \\
Root length, cm & 49 & $4.95 \pm 0.41$ & 2.88 & 58.19 & 0.14 & 0.80 \\
Vigor index, $\%$ & 49 & $1057.96 \pm 92.84$ & 649.85 & 61.42 & 0.03 & 0.75 \\
\hline
\end{tabular}

Tab. 4. Basic statistics for the development of irradiated and non-irradiated bean seeds, 11.06.2014

\begin{tabular}{ccccccc}
\hline Issue & $\mathrm{n}$ & $\mathrm{X} \pm \mathrm{S}_{\mathrm{y}}$ & $\mathrm{s}$ & $\mathrm{CV} \%$ & Skewness & Kurtosis \\
\hline Stem length, $\mathrm{cm}$ & 49 & $6.89 \pm 0.67$ & 4.71 & 68.36 & 0.18 & 1.15 \\
Root length, cm & 49 & $5.81 \pm 0.53$ & 3.69 & 63.52 & -0.06 & 0.96 \\
Vigor index, $\%$ & 49 & $1142.45 \pm 106.76$ & 747.30 & 65.41 & 0.05 & 1.09 \\
\hline
\end{tabular}


Tab. 5. Significance of differences $[\mathrm{cm}]$ between the stem and roots lengths within non-irradiated and irradiated electromagnetic field, 8.06.2014

\begin{tabular}{|c|c|c|c|c|c|}
\hline No.crt. & \multicolumn{2}{|c|}{ Differences } & DF & $\mathrm{t}$ & $\mathrm{p}$ \\
\hline 1 & $\mathrm{SL}_{1}-\mathrm{SL}_{2}$ & $-0.30^{\mathrm{ns}}$ & 96 & -0.854 & 0.394 \\
\hline 2 & $\mathrm{RL}_{1}-\mathrm{RL}_{2}$ & $-0.14^{\mathrm{ns}}$ & 96 & -0.531 & 0.596 \\
\hline
\end{tabular}

Tab. 6. Significance of differences $[\mathrm{cm}]$ between the stem lengths, roots lengths, and vigor indices within non-irradiated and irradiated electromagnetic field, 11.06.2014

\begin{tabular}{cccccc}
\hline No.crt. & \multicolumn{2}{c}{ Differences } & DF & t & $\mathrm{p}$ \\
\hline 1 & $\mathrm{SL}_{1}-\mathrm{SL}_{2}$ & $-0.82^{\mathrm{ns}}$ & 96 & -0.913 & 0.363 \\
2 & $\mathrm{RL}_{1}-\mathrm{RL}_{2}$ & $-0.86^{\mathrm{ns}}$ & 96 & -1.282 & 0.202 \\
3 & $\mathrm{SVI}_{1}-\mathrm{SVI}_{2}$ & $-84.49^{\mathrm{ns}}$ & 96 & -0.597 & 0.551 \\
\hline $\mathrm{ns}-\mathrm{p}>0.05 \%$ & & &
\end{tabular}

\section{CONCLUSSIONS}

The use of low power microwave irradiation in germination of common bean in laboratory conditions may be taken into consideration for large scale cultivation.

All studied parameters, length of stems, length of roots, and vigour index, revealed positive effects of microwave irradiation, even statistically not significant.

Further research is needed in order to establish appropriate practices for the success of this innovative technique.

Acknowledgements. This paper was published under the frame of European Social Fund, Human Resources Development Operational Programme 2007-2013, project no. POSDRU/159/ $1.5 / \mathrm{S} / 132765$

\section{REFFERENCES}

1. Aladjadjiyan A (2007). The use of physical methods for plant growing stimulation in Bulgaria, Central European Agriculture Journal, Volume 8, No. 3: 369-380.

2. Aladjadjiyan A (2011). Ultrasonic stimulation of the development of lentils and wheat seedlings, Romanian journal of biophysics, Vol. 21, No. 3: 179-187.
3. Cretescu I, Caprita R, Velicevici G, Ropciuc S, Buzamat G (2013). Response of Barley Seedlings to Microwaves at $2.45 \mathrm{GHz}$. Animal Science and Biotechnologies, 46 (1): 14-19.

4. Lakshmappa R, Mishra S, Ramachandran V, Bhatia MS (2011).Effects of Low-Power Microwave Fields on Seed Germination and Growth Rate, Journal of Electromagnetic Analysis and Applications, 3: 165-171.

5. Muntean LS, Cernea S, Morar G, Duda M, Vârban D, Muntean S (2011). Fitotehnie, Ed. Risoprint, Cluj-Napoca.

6. Odagiu A, Oroian I, Paulette L, Bordea D, Iederan C, Mălinaş C (2012)., Study Concerning the Influence of Selenium Supplements on Crude Chemical Composition of Allium sativum L., de Cenad Abstract Variety, ProEnvironment 5(12): $200-203$.

7. Podlesny J, Stochmal A, Misiak LE, Podlesna A (2012). Effect of laser light treatment on some biochemical and physiological processes in seeds and seedlings of white lupine and faba bean, Plant Growth Regul, 67: 227-233.

8. Rãcuciu M, Creangã D, Horga I, (2008). Plant growth under static magnetic field influence, Romanian Journal of Physiscs, Vol. 53, Nos. 1-2, P. 353-359, Bucharest.

9. Surducan E, Surducan, Halmagyi A (2012). Plant growth stimulation in microwave field, Patent RO125068B1-2012.

10. ***, http://www.licor.com/env/pdf/light/RMB

11. ***, STATISTICA v 7.0 Office for Windows 